\title{
Evaluation of the Prognostic Factors Effective on Local Recurrence in Atypical Meningiomas
}

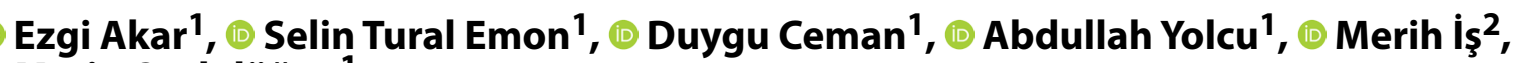 \\ Metin Orakdöğen ${ }^{1}$ \\ ${ }^{1}$ Department of Neurosurgery, Haydarpasa Numune Traninig and Research Hospital, Istanbul, Turkey \\ ${ }^{2}$ Department of Neurosurgery, Fatih Sultan Mehmet Traninig and Research Hospital, Istanbul, Turkey
}

\begin{abstract}
Introduction: Meningiomas are the most common brain tumors and account for $13 \%-26 \%$ of intracranial tumors. Approximately, 5\%-7\% of the meningiomas are termed as atypical meningiomas. The prognosis in patients with benign meningioma (Grade I) is generally very favorable. The outcome for patients with atypical meningioma is progression that is rapid and more invasive.

Methods: We retrospectively analyzed 35 patients with atypical meningiomas who underwent surgery. Patients'age at diagnosis, gender, tumor location, Simpson grade, local tumor recurrence, and treatment with radiation therapy were evaluated.

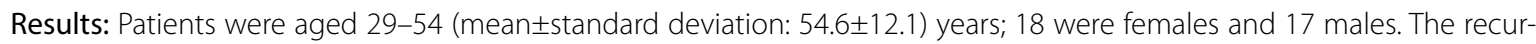
rence rate was $6 / 35$ (17.1\%). Recurrence was found two times more in females. The parasagittal location of the tumor was most common in $66.6 \%$ cases. One-half of the patients did not receive adjuvant radiotherapy (RT). Patients characterized with Simpson Grade I showed lower recurrence rate compared to Grade III.

Discussion and Conclusion: Atypical meningioma recurs more frequently than Grade I lesions. The current management of atypical meningioma is maximal safe resection of tumor followed by adjuvant RT. Adjuvant RT following surgical resection is recommended particularly for incompletely excised tumors or tumors located in the parasagittal area or posterior fossa. In our study, the resection grade was identified as one of the most important factors affecting the prognosis.
\end{abstract}

Keywords: Atypic meningioma; radiotherapy; surgery.

$\mathrm{M}$ eningiomas constitute $13 \%-26 \%$ of brain tumors and are the most common intracranial tumors, with an annual incidence of 61100 per $100.000{ }^{[1]}$. According to the 2007 World Health Organization (WHO) classification, meningiomas are classified into 3 histopathological groups (benign, atypical, and malignant) and 15 subtypes (meningothelial, fibrous, transitional, psammomatous, angiomatous, microcystic, secretory, lymphoplasmacytic, metaplastic, chordoid, clear cell, atypical, rhabdoid, and anaplastic). Most of the meningiomas (90\%) are benign, well-confined, slow-growing tumors and classified as WHO Grade $1{ }^{[2,3]} ; 5 \%-7 \%$ of them are considered atypical (Grade 2 ), and only $1 \%-3 \%$ of them anaplastic or malignant (Grade 3) tumors ${ }^{[4]}$. Although $20 \%$ of Grade 1 meningiomas are histopathologically benign, they are clinically aggressive, indicating that some of the meningiomas have borderline characteristics ${ }^{[5]}$.

Therefore, the classification of meningiomas had to be

Correspondence (İletişim): Ezgi Akar, M.D. Haydarpasa Numune Egitim ve Arastirma Hastanesi, Beyin ve Sinir Cerrahisi Kliniği, Istanbul, Turkey Phone (Telefon): +90 2163868263 E-mail (E-posta): ezgiaycicek@gmail.com

Submitted Date (Başvuru Tarihi): 29.01.2018 Accepted Date (Kabul Tarihi): 06.04.2018

Copyright 2019 Haydarpaşa Numune Medical Journal

OPEN ACCESS This is an open access article under the CC BY-NC license (http://creativecommons.org/licenses/by-nc/4.0/) 
renewed. Based on the revisions in the 2016 WHO classification, the presence of cerebral invasion is diagnosed as atypical meningioma, regardless of histopathological features ${ }^{[6]}$. The recurrence of atypical meningioma is associated with increased mortality and morbidity. The risk factors of recurrence in benign meningioma include age $<40$ years, meningiomas of the skull base, and male gender. However, the effect of these factors on the prognosis in atypical meningiomas remains controversial ${ }^{[7-9]}$. Maximal safe resection is recommended in cases with atypical meningioma for disease control, but the effect of total surgical resection on survival is unclear. Adjuvant radiotherapy (RT) is recommended in patients undergoing subtotal resection, whereas postoperative $\mathrm{RT}$ is controversial in patients undergoing total surgical excision ${ }^{[7]}$.

The effect of RT on the long-term survival is remains unknown. There is still no consensus on the factors affecting the recurrence of atypical meningiomas and their treatment. We aimed to determine the possible risk factors for local recurrence in atypical meningioma cases.

\section{Materials and Methods}

A total of 35 atypical meningioma cases operated through microsurgery between 2007 and 2016 were retrospectively reviewed. Patients were evaluated according to age, gender, tumor localization of tumor, Simpson grade, and postoperative adjuvant RT.

\section{Statistical Evaluation}

Descriptive statistics were used to define continuous variables (average, standard deviation [SD], minimum, median, and maximum). The student's t-test was used for comparing two independent and normally distributed continuous variables, whereas the Mann-Whitney $U$ test was used for comparing two independent variables with non-normal distribution. The chi-square test (or Fisher Exact test where appropriate) was used to examine the relationship between categorical variables. The statistical significance level was determined as 0.05 . The analyses were performed using the MedCalc Statistical Software, version 12.7.7 (MedCalc Software bvba, Ostend, Belgium; http://www.medcalc.org; 2013).

\section{Results}

Seventeen (48.6\%) patients were males and 18 (51.4\%) were females. Recurrence was observed in $11.8 \%$ ( 2 cases) of male and in $22.2 \%(4 / 35)$ of female patients. Although recurrence was twice as high in female patients, no significant statistical difference was found between the two genders. The age of patients ranged between 29 and 54 years, and the mean $\pm S D$ age was $54.6 \pm 12.1$ years.

There was no significant difference between the patients in terms of age distribution. In $48.6 \%$ (17/35) of the cases, the tumor was localized on convexity and in the parasagittal region in $42.8 \%$ (15/35), sphenoid wing in 5.8\% (2/35), and petrous apex in $2.8 \%(1 / 35)$ of the cases. Recurrence was observed in $17.1 \%(6 / 35)$ of the cases. The tumor was located in the parasagittal location in $66.6 \%$ of the patients with recurrence, but the tumor localization did not have a significant effect on recurrence (Table 1). The postoperative resection rate in meningiomas was evaluated according to the Simpson rating system.

Grade 1 is the total removal of the tumor macroscopically, with dural, venous, and bone involvement, if any; Grade 5 refers to only simple decompression or biopsy. In Simpson Grade 1 tumors, the recurrence rate (7.4\%) was significantly lower than Grade 2 (50\%) and 3 (50\%) tumors (Table 2). Nineteen cases $(54.2 \%)$ received adjuvant RT.

Table 1. Relation between localization of the tumor and recurrence

\begin{tabular}{lccc}
\hline & \multicolumn{2}{c}{ Recurrence } & p \\
\cline { 2 - 3 } & No & Yes & \\
& $\mathbf{n}(\%)$ & $\mathbf{n}(\%)$ & \\
\hline Localization & & & \\
Skull base & $3(9.7)$ & $0(0.0)$ & \\
Convexity & $14(45.2)$ & $2(28.6)$ & \\
Parasagittal & $12(38.7)$ & $5(71.4)$ & \\
Cerebellar convexity & $2(6.5)$ & $0(0.0)$ & \\
Localization & & & \\
Frontal & $7(22.6)$ & $1(14.3)$ \\
Frontoparietal & $2(6.5)$ & $2(28.6)$ \\
Frontotemporal & $2(6.5)$ & $0(0.0)$ \\
Occipital & $3(9.7)$ & $0(0.0)$ \\
Parietal & $8(25.8)$ & $4(57.1)$ & \\
Petrous & $1(3.2)$ & $0(0.0)$ \\
Cerebellar & $2(6.5)$ & $0(0.0)$ \\
Sphenoid Wing & $2(6.5)$ & $0(0.0)$ \\
Temporal & $2(6.5)$ & $0(0.0)$ \\
Temporaparyetal & $2(6.5)$ & $0(0.0)$ \\
\hline
\end{tabular}

*Fisher's Exact p.

Tablo 2. Relation between Simpson grade and recurrence

\begin{tabular}{cccc}
\hline & \multicolumn{2}{c}{ Recurrence } & \\
\cline { 2 - 3 } & No (\%) & Yes (\%) & p \\
\hline Simpson & & & \\
1 & $27(77.2)$ & $2(7.4)$ & $<0.05^{*}$ \\
2 & $6(17.1)$ & $3(50)$ & \\
3 & $2(5.7)$ & $1(50)$ & \\
\hline
\end{tabular}




\section{Discussion}

Atypical meningiomas constitute $5 \%-7 \%$ of all intracranial meningiomas (Grade 2). However, the incidence of atypical meningioma increased with the addition of the "presence of single brain invasion" criterion in the WHO 2016 classification ${ }^{[6]}$. In a case series of Perry et al, atypical meningiomas were identified in $24.3 \%$ of 643 cases ${ }^{[10]}$. The 5 -year survival rate of atypical meningiomas was $67.5 \%-75 \%$, and the mean survival time was $10-14$ years ${ }^{[11]}$.

Atypical meningiomas can be asymptomatic. However, varying symptoms, such as headache, vertigo, cranial nerve findings, and hydrocephalus, are also observed depending on the tumor location, size, mass effect, and growth rate ${ }^{[12]}$.

A magnetic resonance imaging scan is the most useful diagnostic procedure. The presence of peritumoral edema and heterogeneous enhancement in $\mathrm{T} 2$ sequences and hyperintensity in a diffusion-weighted imaging sequence suggests atypical meningioma (Fig. 1). In some Grade 1 large meningiomas, calcification is heterogeneous if there is cystic degeneration ${ }^{[12-15]}$. The shape of the tumor may not always give information about its nature.

Although irregularly shaped tumors are thought to be aggressive, histopathologically benign meningiomas with impaired focal feeding or venous drainage may also have irregular contours $[2,12,16]$. Therefore, histopathologically,

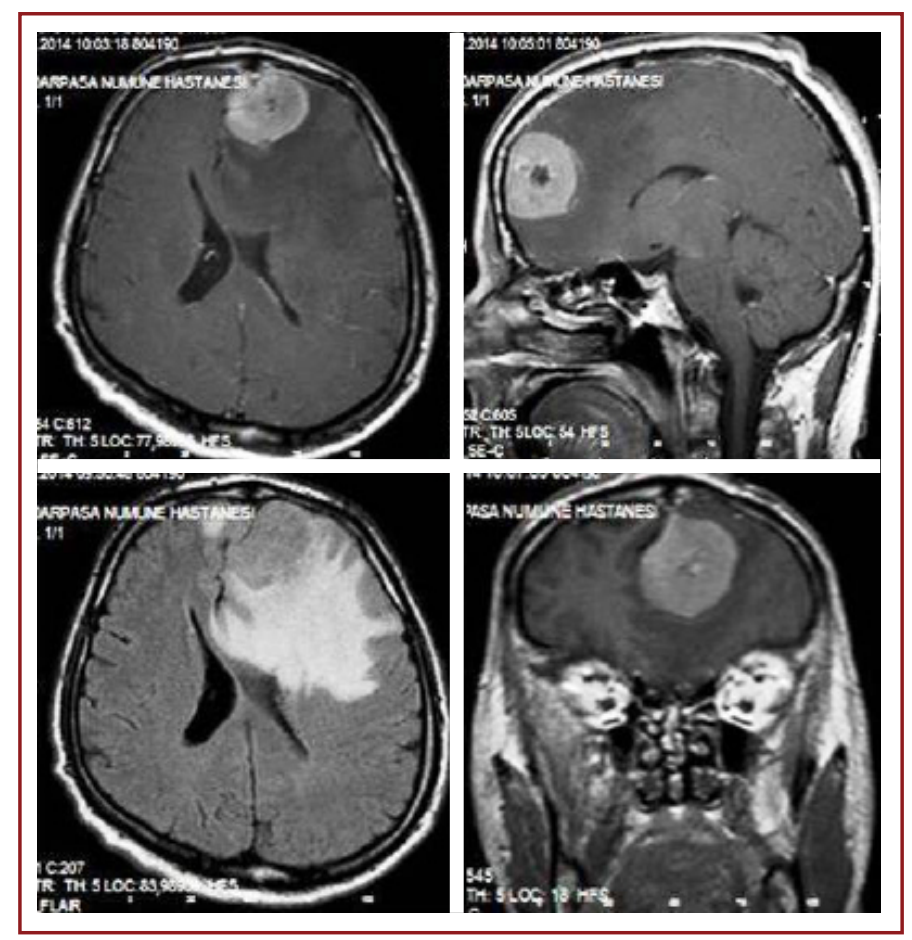

Figure 1. A case of atypical meningioma located in the falx. Heterogeneous enhancement and peritumoral edema are observed.
$30 \%$ of Grade 1 tumors were classified as atypical, and survival rates in patients with Grade 1 tumors are similar to Grade 2 tumors ${ }^{[17]}$.

In atypical meningiomas, many factors that affect the prognosis and survival have been studied, and there is still no consensus. In the current series, female gender had worse prognosis, whereas in some series, gender had no effect on the total survival ${ }^{[9,18]}$. In our study, although a 2 -fold increased recurrence rate was observed in female patients, no statistically significant difference was found between both genders. Pasquier et al. ${ }^{[18]}$ found that age above 60 years is a worse prognostic factor, and Milosevic et al. [19] showed that age $<40$ years was a good prognostic factor. There was no significant difference in terms of age distribution in our patients.

The preoperative Karnofsky performance value is effective on the survival, and overall survival is low in patients with a poor general condition ${ }^{[9]}$. The location of atypical meningiomas is also effective on the prognosis of the disease. The recurrence rates were higher in meningiomas localized in the parasagittal region, falx cerebri, and posterior fossa, with lower overall survival (Fig. 2). The reason for this is that total resection of the tumors localized on this region is challenging due to their proximity to the sinus ${ }^{[9,20,21]}$. Further, $66.6 \%$ of our cases had parasagittal tumors. However, tumor localization did not have a statistically significant ef-

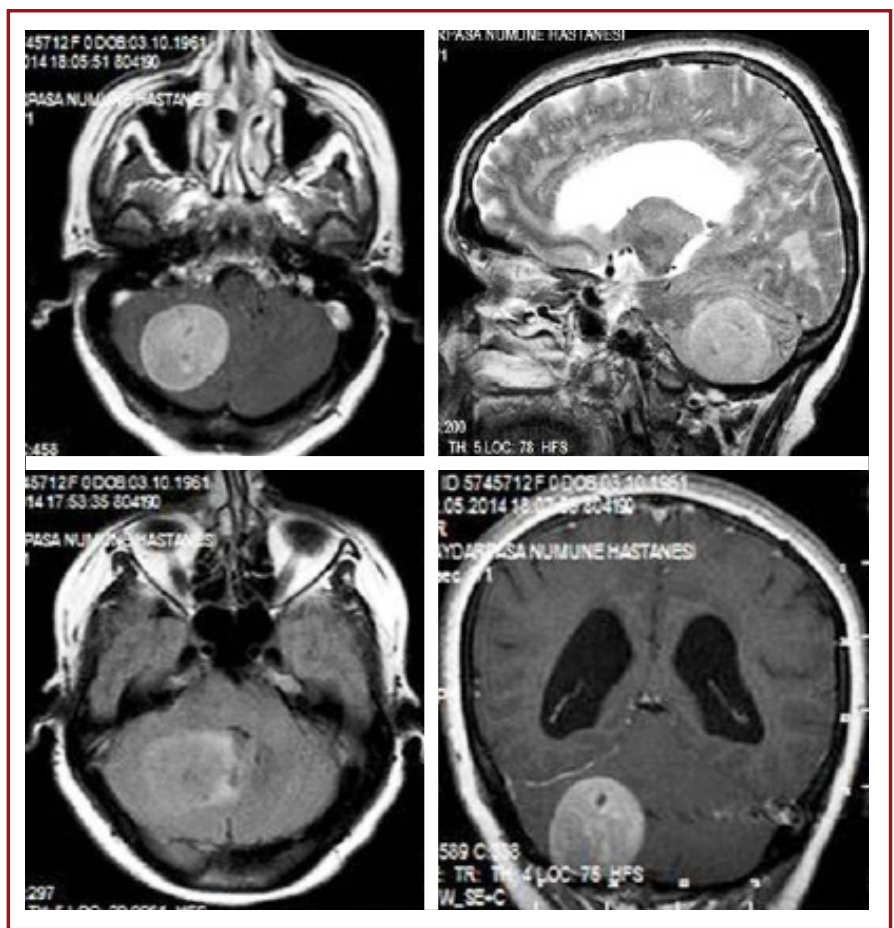

Figure 2. Magnetic resonance imaging of atypical meningioma located in the posterior fossa. In T1 iso-hypointense and T2 hyperintense heterogeneous contrast enhancement. 


\section{fect on recurrence.}

The most important step in the treatment of atypical meningiomas is local control of the disease, and maximal safe resection is recommended ${ }^{[7,22]}$. The probability of local progressive disease is quite high in patients who underwent subtotal resection. In a study, recurrence was seen 7-8 times more frequently in atypical meningiomas during a follow-up period of 3-5 years compared to Grade 1 meningiomas, and the mortality rate was also twice as high [10]. The 5 -year survival rate was $67.5 \%-97.5 \%{ }^{[23]}$. The Simpson rating is an important prognostic marker. In the present study, the Simpson grade was found to be associated with recurrence. In patients with Simpson Grade 3 resection, a recurrence rate of $50 \%$ was observed. The recurrence rate was significantly lower in the Simpson Grade 1 group.

No standard approach has yet been followed in the treatment of these tumors. Postoperative RT is controversial $[7,9,24]$. In recent studies, adjuvant RT has been recommended in patients who had undergone subtotal resection, but there is still no consensus in cases that had undergone maximal tumor resection. Wang et al. ${ }^{[9]}$ reported that adjuvant RT did not contribute additionally to the decrease in the local recurrence of tumors in patients with maximal resection, whereas local disease control with adjuvant RT was highly effective in subtotal resection cases. Because of the challenges in the total resection of atypical meningiomas located in the posterior fossa and parasagittal regions, routine adjuvant RT is recommended for such cases ${ }^{[9]}$. However, it is noted that in recurrent tumors of atypical meningioma, patients who underwent adjuvant RT, Grade 3 pathology may be detected, and adjuvant RT may increase tumor aggressiveness ${ }^{[7,24]}$. Adjuvant RT is not recommended in patients with maximal tumor resection, considering the short -term (nausea, vomiting, weakness, edema, hair loss, etc.) and long-term (radiation necrosis, focal neurological deficit, secondary malignancies) side effects of RT ${ }^{[7]}$. Therefore, Aizer et al. ${ }^{[7]}$ did not perform RT in $76 \%$ of patients with atypical meningioma who had undergone subtotal resection. In our study, $54.2 \%$ of the patients underwent postoperative adjuvant RT.

In conclusion, many factors that affect the prognosis and recurrence of atypical meningiomas have been investigated. The most important step in the treatment is local control of the disease. En bloc surgery to the maximum extent is recommended for prolonging the overall survival and ensuring recurrence-free survival. In patients with subtotal resection, the incidence rate of local progressive disease is high and adjuvant $\mathrm{RT}$ is usually required during the postoperative period. The present study showed that the degree of resection is an effective factor on local recurrence in parallel with literature data.

Peer-review: Externally peer-reviewed.

Authorship Contributions: Concept: E.A., M.I.; Design: M.O., S.T.E.; Data Collection or Processing: A.Y.; Analysis or Interpretation: D.C.; Literature Search: E.A.; Writing: E.A.

Conflict of Interest: None declared.

Financial Disclosure: The authors declared that this study received no financial support.

\section{References}

1. Riemenschneider MJ, Perry A, Reifenberger G. Histological classification and molecular genetics of meningiomas. Lancet Neurol 2006;5:1045-54. [CrossRef]

2. Kawahara Y, Nakada M, Hayashi Y, Kai Y, Hayashi Y, Uchiyama $\mathrm{N}$, et al. Prediction of high-grade meningioma by preoperative MRI assessment. J Neurooncol 2012;108:147-52. [CrossRef]

3. Fuller GN, Scheithauer BW. The 2007 Revised World Health Organization (WHO) Classification of Tumours of the Central Nervous System: newly codified entities. Brain Pathol 2007;17:304-7. [CrossRef]

4. Louis DN, Ohgaki H, Wiestler OD, Cavenee WK, Burger PC, Jouvet $A$, et al. The 2007 WHO classification of tumours of the central nervous system. Acta Neuropathol 2007;114:97-109.

5. Ayerbe J, Lobato RD, de la Cruz J, Alday R, Rivas JJ, Gómez PA, et al. Risk factors predicting recurrence in patients operated on for intracranial meningioma. A multivariate analysis. Acta Neurochir (Wien) 1999;141:921-32. [CrossRef]

6. Louis DN, Perry A, Reifenberger $G$, von Deimling A, FigarellaBranger D, Cavenee WK, et al. The 2016 World Health Organization Classification of Tumors of the Central Nervous System: a summary. Acta Neuropathol 2016;131:803-20. [CrossRef]

7. Aizer AA, Arvold ND, Catalano P, Claus EB, Golby AJ, Johnson $M D$, et al. Adjuvant radiation therapy, local recurrence, and the need for salvage therapy in atypical meningioma. Neuro Oncol 2014;16:1547-53. [CrossRef]

8. Schwarz AJ, Danckaert A, Reese T, Gozzi A, Paxinos G, Watson $C$, et al. A stereotaxic MRI template set for the rat brain with tissue class distribution maps and co-registered anatomical atlas: application to pharmacological MRI. Neuroimage 2006;32:538-50. [CrossRef]

9. Wang YC, Chuang CC, Wei KC, Chang CN, Lee ST, Wu CT, et al. Long Term Surgical Outcome and Prognostic Factors of Atypical and Malignant Meningiomas. Sci Rep 2016;6:35743.

10. Perry A. Menigiomas. Russell and Rubinstein's Pathology of Tumors of the Nervous System. R.M. McLendon RE, Bigner DD, editors. London: Hodder Arnold; 2006. pp. 427-474.

11. Mut M. Atipik ve malign menenjiomlar. Türk Nöroşirurji Dergisi 2011;21:173-7.

12. Roser F, Nakamura M, Jacobs $C$, Vorkapic P, Samii M. Sphenoid wing meningiomas with osseous involvement. Surg Neurol 
2005;64:37-43. [CrossRef]

13. Filippi CG, Edgar MA, Uluğ AM, Prowda JC, Heier LA, Zimmerman RD. Appearance of meningiomas on diffusion-weighted images: correlating diffusion constants with histopathologic findings. AJNR Am J Neuroradiol 2001;22:65-72.

14. Kaplan RD, Coons S, Drayer BP, Bird CR, Johnson PC. MR characteristics of meningioma subtypes at 1.5 tesla. J Comput Assist Tomogr 1992;16:366-71. [CrossRef]

15. Simis A, Pires de Aguiar PH, Leite CC, Santana PA Jr, Rosemberg S, Teixeira MJ. Peritumoral brain edema in benign meningiomas: correlation with clinical, radiologic, and surgical factors and possible role on recurrence. Surg Neurol 2008;70:471-7. [CrossRef]

16. McGovern SL, Aldape KD, Munsell MF, Mahajan A, DeMonte F, Woo SY. A comparison of World Health Organization tumor grades at recurrence in patients with non-skull base and skull base meningiomas. J Neurosurg 2010;112:925-33. [CrossRef]

17. Liu Y, Chotai S, Chen M, Jin S, Qi ST, Pan J. Preoperative radiologic classification of convexity meningioma to predict the survival and aggressive meningioma behavior. PLoS One 2015;10:e0118908. [CrossRef]

18. Pasquier D, Bijmolt S, Veninga T, Rezvoy N, Villa S, Krengli M, et al.; Rare Cancer Network. Atypical and malignant meningioma: outcome and prognostic factors in 119 irradiated pa- tients. A multicenter, retrospective study of the Rare Cancer Network. Int J Radiat Oncol Biol Phys 2008;71:1388-93.

19. Milosevic MF, Frost PJ, Laperriere NJ, Wong CS, Simpson WJ. Radiotherapy for atypical or malignant intracranial meningioma. Int J Radiat Oncol Biol Phys 1996;34:817-22. [CrossRef]

20. Klostermann EC, Kane AJM, Shimamura AP. Parietal activation during retrieval of abstract and concrete auditory information. Neuroimage 2008;40:896-901. [CrossRef]

21. Dziuk TW, Woo S, Butler EB, Thornby J, Grossman R, Dennis WS, et al. Malignant meningioma: an indication for initial aggressive surgery and adjuvant radiotherapy. J Neurooncol 1998;37:177-88. [CrossRef]

22. Aizer AA, Bi WL, Kandola MS, Lee EQ, Nayak L, Rinne ML, et al. Extent of resection and overall survival for patients with atypical and malignant meningioma. Cancer 2015;121:4376-81.

23. Jääskeläinen J. Seemingly complete removal of histologically benign intracranial meningioma: late recurrence rate and factors predicting recurrence in 657 patients. A multivariate analysis. Surg Neurol 1986;26:461-9. [CrossRef]

24. Engenhart-Cabillic R, Farhoud A, Sure U, Heinze S, Henzel M, Mennel HD, et al. Clinicopathologic features of aggressive meningioma emphasizing the role of radiotherapy in treatment. Strahlenther Onkol 2006;182:641-6. [CrossRef] 